\title{
EVALUATION OF GRAFT UPTAKE IN TYPE 1 TYMPANOPLASTY WITH DRY AND WET TEMPORALIS FASCIA GRAFT
}

\author{
Sadarudheen Ahmed Mohammed Islah', Thasneem Banu Thelakkadan Palliyalippadi²
}

${ }^{1}$ Additional Professor, Department of ENT, Government Medical College, Alappuzha. 2Junior Resident, Department of ENT, Government Medical College, Kottayam.

ABSTRACT
BACKGROUND
Objective - To compare the uptake of graft in type 1 tympanoplasty done using dry and wet temporalis fascia in patients attending
Department of ENT Govt. Medical College Kottayam during a period of 1 year.

\section{MATERIALS AND METHODS}

This study was conducted in 60 patients who underwent type 1 tympanoplasty from $1^{\text {st }}$ May 2014 to $30^{\text {th }}$ April 2015. The patients were grouped into two with 30 cases in each. In Group 1, dry temporalis fascia was used as graft material and in Group 2 wet temporalis fascia was used. Post-aural or transcanal approach with underlay grafting of temporalis fascia was done in all cases. Alternative cases were grouped into dry temporalis fascia and wet temporalis fascia graft group. All patients were followed up 2 weeks and 6 weeks after the surgery and were evaluated for graft uptake. Successful graft uptake was defined as having no perforation, retraction or lateralisation of tympanic membrane graft as assessed by otoscope.

\section{RESULTS}

There was 73.33\% graft uptake rate in group 1 (dry group) as compared to 63.33\% in group 2 (wet group). The difference was not statistically significant. There is significant relationship between success rate of tympanoplasty and age of the patient, size and site of perforation, middle ear mucosal status and Eustachian tube function. Graft uptake was least for those with $>40$ years of age. Graft uptake rate decreased with increasing size of perforation and poor Eustachian tube function. Graft was failure in all cases with oedematous middle ear mucosa.

\section{CONCLUSION}

Graft uptake was superior when using dry temporalis fascia graft. There was $73.33 \%$ graft uptake rate in group 1 (dry temporalis fascia graft) compared to $63.33 \%$ in group 2 (wet temporalis fascia graft).

\section{KEYWORDS}

Chronic Otitis Media, Type 1 Tympanoplasty, Dry Temporalis Fascia Graft, Wet Temporalis Fascia Graft.

HOW TO CITE THIS ARTICLE: Islah SAM, Palliyalippadi TBT. Evaluation of graft uptake in type 1 tympanoplasty with dry and wet temporalis fascia graft. J. Evolution Med. Dent. Sci. 2016;5(104):7684-7689, DOI: 10.14260/jemds/2016/1733

\begin{abstract}
BACKGROUND
Chronic otitis media (COM) is defined as a chronic inflammation of the middle ear and mastoid cavity, which presents with recurrent ear discharges or otorrhoea through a tympanic membrane perforation. Prevalence surveys show that the global burden of illness from COM involves 65-330 million individuals with draining ears, $60 \%$ of whom (39-200 million) suffer from significant hearing impairment. COM accounts for 28000 deaths and a disease burden of over 2 million DALYs. ${ }^{1}$

The diagnosis of COM needs to be made earlier so that it may be possible to prevent its long-term effects especially on hearing impairment. There are various intratemporal and intracranial complications likely in patients with COM and the mortality rate of these remains $8 \%{ }^{2}$ In view of this it is imperative to treat patients with $\mathrm{COM}$ and the mainstay of therapy remains surgical.
\end{abstract}

Financial or Other, Competing Interest: None.

Submission 22-11-2016, Peer Review 16-12-2016,

Acceptance 22-12-2016, Published 29-12-2016.

Corresponding Author:

Dr. Sadarudheen Ahmed Mohammed Islah,

Government Medical College,

Vandanam P. O.,

Alappuzha.

E-mail: drsadarudeen@yahoo.com

DOI: $10.14260 /$ jemds $/ 2016 / 1733$
American Academy of Ophthalmology And Otolaryngology Committee on Conservation of Hearing defined tympanoplasty as "a procedure to eradicate disease in the middle ear and to reconstruct the hearing mechanism, with or without tympanic membrane grafting."

Type 1 tympanoplasty refers to repair of the TM without altering the ossicular system. The procedure includes exploration of the middle ear to inspect and ensure normality of the ossicles. ${ }^{3}$ The term tympanoplasty was first used in 1953 by Wullstein to describe surgical techniques for reconstruction of the middle ear hearing mechanism that had been impaired or destroyed by chronic ear disease. A critical problem early in the development of tympanoplasty was finding an ideal graft material for tympanic membrane grafting which is still in debate. Autologous graft materials such as temporalis fascia, tragal perichondrium, cartilage, fat, and fascia lata have stood the test of time in repairing tympanic membrane perforations. These graft materials vary regarding their ease of harvesting, preparation time, placement ease, viability and consequently the graft uptake and hearing improvement. However, due to its anatomic proximity, translucency, and suppleness, temporalis fascia is the most preferred grafting materials among the otologists and successful closure is anticipated in approximately $90 \%$ of primary tympanoplasties. Some surgeons use temporalis fascia in the dry form, whereas others in the wet form. 
Using a dry temporalis fascia graft is preferred by majority of surgeons because a dry graft is easier to slide and manipulate beneath the tympanomeatal flap. It has a low metabolic rate and high collagen content and has been assumed by many that temporalis fascia is viable. But fascia is devitalised after scraping and drying and the number of fibroblast nuclei is higher in the wet graft. The dry graft undergoes considerable shrinkage once it is placed in the moist environment of middle ear, thereby losing surface contact with the anterior margin of the perforation if not tucked in adequately leading to failure of tympanoplasty. A few studies have been conducted comparing success rate using dry and wet temporalis fascia graft. So a study is being planned to compare the take rate of dry temporalis fascia graft with that of wet temporalis fascia graft.

\section{Objective}

To compare the uptake of graft in type 1 tympanoplasty done using dry and wet temporalis fascia in patients attending Department of ENT, Govt. Medical College Kottayam during a period of 1 year.

\section{MATERIALS AND METHODS \\ Study Design}

Descriptive longitudinal study

\section{Inclusion Criteria}

Patients with chronic otitis media, mucosal type, inactive for at least 6 weeks, above the age of 18 years.

\section{Exclusion Criteria}

1. Patients with chronic otitis media, active disease.

2. COM squamosal type.

3. COM with complications.

4. Below 18 years.

5. Patients with previous major ear surgeries and or deformities of external auditory canal.

\section{Procedure in Detail}

After history taking patients were subjected to detailed clinical examination to detect central perforation of tympanic membrane and to exclude other diseases of ear. Then, patients were subjected to audiological investigations and X-ray, both mastoids Schuller's view.

Then, tympanoplasty was done under local anaesthesia after obtaining written informed consent. Post-aural or transcanal approach with underlay grafting of temporalis fascia was done in all cases. Alternative cases were grouped into dry temporalis fascia and wet temporalis fascia graft group. In case of dry graft, after harvesting the temporalis fascia graft, it was teased out to a thin uniform layer and allowed to dry where as in case of wet graft after harvesting the graft, it was immersed in normal saline. Then, graft was placed by the underlay technique.

All patients were followed up 2 weeks and 6 weeks after surgery and were evaluated for graft uptake. Successful graft uptake was defined as having no perforation, retraction or lateralisation of tympanic membrane graft as assessed by otoscope.

\section{Data Management and Statistical Analysis}

The data was entered in Microsoft Excel and further analysis was done using software SPSS. The level of statistical significance was $p$ value of $<0.05$.

\section{RESULTS}

The patients were grouped into two with 30 cases in each. In Group 1 dry temporalis fascia was used as graft material and in Group 2 wet temporalis fascia was used. Observations were as follows:

Age distribution of the study population ranged from 18 to 54 years of age. Most of the patients were in the age group 2130 years in both groups (43.3\% in group 1 and $36.7 \%$ in group 2).

Females were predominating in both groups. $66.7 \%$ were females in group 1 and $76.7 \%$ were females in group 2 .

\begin{tabular}{|c|c|c|}
\hline Symptom & Group 1 & Group 2 \\
\hline Ear discharge & $30(100 \%)$ & $29(96.7 \%)$ \\
\hline Hard of hearing & $20(66.7 \%)$ & $17(56.7 \%)$ \\
\hline Ear ache & $2(6.7 \%)$ & $4(13.3 \%)$ \\
\hline Table 1. Distribution of Symptoms of Study Population \\
\hline
\end{tabular}

$100 \%$ patients of group 1 and $96.7 \%$ of group 2 had ear discharge as symptom.

In group 1, 6.7\% patients had diabetes mellitus, $6.7 \%$ patients had hypertension and $3.3 \%$ patients had bronchial asthma. In group 2, there was history of diabetes and hypertension in $10 \%$ of patients each. Rest of patients were without any history of significant past illnesses.

Left-sided CSOM was more common $(50 \%)$ in group 1 , whereas right and left-sided CSOM were equal ( $40 \%$ each) in group 2.

\begin{tabular}{|c|c|c|}
\hline Size of Perforation & Group 1 & Group 2 \\
\hline Small & $6(20 \%)$ & $2(6.6 \%)$ \\
\hline Medium & $10(33.3 \%)$ & $14(46.7 \%)$ \\
\hline Large & $14(46.7 \%)$ & $14(46.7 \%)$ \\
\hline Total & $30(100 \%)$ & $30(100.0 \%)$ \\
\hline \multicolumn{2}{|c|}{ Table 2. Distribution of Study Population } \\
According to Size of Perforation \\
\hline
\end{tabular}

Majority (46.7 \%) of patients in group 1 had large central perforations, whereas in group 2 large and medium-sized perforations were equally distributed ( $46.7 \%$ each).

\begin{tabular}{|c|c|c|}
\hline Site of Perforation & Group 1 & Group 2 \\
\hline Anterior & $10(33.3 \%)$ & $7(23.3 \%)$ \\
\hline Posterior & $4(13.3 \%)$ & $7(23.3 \%)$ \\
\hline $\begin{array}{c}\text { Involving both } \\
\text { anterior \& posterior }\end{array}$ & $16(53.4 \%)$ & $16(53.4 \%)$ \\
\hline Total & $30(100 \%)$ & $30(100 \%)$ \\
\hline \multicolumn{3}{|c|}{$\begin{array}{l}\text { Table 3. Distribution of Study Population } \\
\text { According to Site of Perforation }\end{array}$} \\
\hline
\end{tabular}

$53.4 \%$ of patients in each group had perforation involving both anterior and posterior quadrant.

Most common approach was transcanal (90\% in group 1 and $83.3 \%$ in group 2). Post-aural approach was used in 3 cases in group 1 and 5 cases in group 2.

Middle ear mucosa was normal in most of the patients in both groups. Only $13.3 \%$ and $10 \%$ had oedematous middle ear mucosa in group 1 and group 2 respectively.

Eustachian tube function was poor in majority of patients (56.7\%) in group 1 and $53.3 \%$ in group 2. 
Mean PTA of group 1 is $34.04 \mathrm{~dB}$ and standard deviation is 12.49 and that of group 2 is $33.92 \mathrm{~dB}$ and standard deviation is 8.14 .

\begin{tabular}{|c|c|c|c|c|}
\hline \multirow{2}{*}{$\begin{array}{c}\text { Size of } \\
\text { Perforation }\end{array}$} & \multicolumn{2}{|c|}{ Group 1 } & \multicolumn{2}{c|}{ Group 2 } \\
\cline { 2 - 5 } & $\begin{array}{c}\text { Mean } \\
\text { PTA }\end{array}$ & $\begin{array}{c}\text { Standard } \\
\text { Deviation }\end{array}$ & $\begin{array}{c}\text { Mean } \\
\text { PTA }\end{array}$ & $\begin{array}{c}\text { Standard } \\
\text { Deviation }\end{array}$ \\
\hline Small & 21.53 & 8.23 & 21.65 & 9.4 \\
\hline Medium & 32.14 & 9.04 & 29.97 & 6.75 \\
\hline Large & 40.78 & 11.89 & 39.63 & 4.53 \\
\hline Total & $\mathbf{3 4 . 0 5}$ & $\mathbf{1 2 . 4 9}$ & $\mathbf{3 3 . 9 2}$ & $\mathbf{8 . 1 4}$ \\
\hline \multicolumn{3}{|c|}{ Table 4. Relationship between Size of } \\
Perforation and PTA in both Groups \\
\hline
\end{tabular}

In group 1-ANOVA TEST F value- 7.46, p value-.003. In group 2-ANOVA TEST F value- 13.9, p value-.000.

\begin{tabular}{|c|c|c|c|c|}
\hline \multirow{2}{*}{$\begin{array}{c}\text { Site Of } \\
\text { Perforation }\end{array}$} & \multicolumn{2}{|c|}{ Group 1 } & \multicolumn{2}{c|}{ Group 2 } \\
\cline { 2 - 5 } & $\begin{array}{c}\text { Pean } \\
\text { PTA }\end{array}$ & $\begin{array}{c}\text { Standard } \\
\text { Deviation }\end{array}$ & $\begin{array}{c}\text { Mean } \\
\text { PTA }\end{array}$ & $\begin{array}{c}\text { Standard } \\
\text { Deviation }\end{array}$ \\
\hline Anterior & 23.46 & 6.72 & 24.25 & 5.82 \\
\hline Posterior & 31.5 & 4.35 & 31.17 & 6.62 \\
\hline $\begin{array}{c}\text { Both } \\
\text { Anterior And } \\
\text { Posterior }\end{array}$ & 41.31 & 11.74 & 39.36 & 4.3 \\
\hline \multicolumn{7}{|c|}{ Total } & $\mathbf{3 4 . 0 5}$ & $\mathbf{1 2 . 4 9}$ & $\mathbf{3 3 . 9 2}$ & $\mathbf{8 . 1 4}$ \\
\hline \multicolumn{4}{|c|}{ Table 5. Relationship between Site of } \\
Perforation and PTA in both Groups \\
\hline
\end{tabular}

In group 1-ANOVA TEST- F value - 10.612, p value-.000. In group 2-ANOVA TEST- F value - 21.391, p value-.000.

\begin{tabular}{|c|c|c|c|}
\hline Graft Type & Graft Taken & Not Taken & Total \\
\hline $\begin{array}{c}\text { Dry } \\
\text { (Group 1) }\end{array}$ & $22(73.33 \%)$ & $8(26.67 \%)$ & $30(100 \%)$ \\
\hline $\begin{array}{c}\text { Wet } \\
\text { (Group 2) }\end{array}$ & $19(63.33 \%)$ & $11(36.67 \%)$ & $30(100 \%)$ \\
\hline Total & $\begin{array}{c}\mathbf{4 1} \\
(\mathbf{6 8 . 3 3} \%)\end{array}$ & $\begin{array}{c}\mathbf{1 9} \\
(\mathbf{3 1 . 6 7 \% )}\end{array}$ & $\begin{array}{c}\mathbf{6 0} \\
\mathbf{( 1 0 0 \% )}\end{array}$ \\
\hline \multicolumn{4}{|c|}{ Table 6. Comparison of Graft } \\
\hline \multicolumn{4}{|c|}{ Uptake in Group 1 and Group 2 } \\
\hline
\end{tabular}

Chi - square -0.693 , df -1 , p value -.405 .

Graft was taken in $73.33 \%$ of dry group and $63.33 \%$ of wet group. The difference is not statistically significant as $p$ value is $>0.05$.

\begin{tabular}{|c|c|c|c|c|}
\hline \multicolumn{3}{|c|}{ Group 1 } & \multicolumn{2}{c|}{ Group 2 } \\
\hline $\begin{array}{c}\text { Age } \\
\text { Group }\end{array}$ & $\begin{array}{c}\text { Graft } \\
\text { Taken }\end{array}$ & $\begin{array}{c}\text { Graft Not } \\
\text { Taken }\end{array}$ & $\begin{array}{c}\text { Graft } \\
\text { Taken }\end{array}$ & $\begin{array}{c}\text { Graft Not } \\
\text { Taken }\end{array}$ \\
\hline $18-20$ & $2(100 \%)$ & 0 & $1(33.33 \%)$ & $2(66.67 \%)$ \\
\hline $21-30$ & $12(92.3 \%)$ & $1(7.7 \%)$ & $10(90.9 \%)$ & $1(9.1 \%)$ \\
\hline $31-40$ & $7(63.64 \%)$ & $4(36.36 \%)$ & $3(37.5 \%)$ & $5(62.5 \%)$ \\
\hline$>40$ & $1(25 \%)$ & $3(75 \%)$ & $5(62.5 \%)$ & $3(37.5 \%)$ \\
\hline Total & $\mathbf{2 2 ( 7 3 . 3 3 )}$ & $\mathbf{8}(\mathbf{2 6 . 6 \% )}$ & $\mathbf{1 9}(\mathbf{6 3 . 3 3} \%)$ & $\mathbf{1 1 ( 3 6 . 6 \% )}$ \\
\hline \multicolumn{4}{|c|}{$\begin{array}{c}\text { Table 7. Relationship between } \\
\text { Age Group and Graft Uptake }\end{array}$} \\
\hline
\end{tabular}

In group 1, there was significant difference in graft uptake between the different age groups studied, with 18-20 age group having maximum graft uptake (100\%) followed by 21 30 age group (92.3\%). Graft uptake was least in $>40$ years (25\%).

Group 2-Chi-square - 7.066, df-3, p value-0.07. In group 2 the graft uptake was maximum in the $21-30$ age group (90.9\%) followed by $>40$ age group $(62.5 \%)$. But this relation was not statistically significant.

\begin{tabular}{|c|c|c|c|c|}
\hline \multirow{2}{*}{$\begin{array}{l}\text { Size of Per- } \\
\text { foration }\end{array}$} & \multicolumn{2}{|c|}{ Group 1} & \multicolumn{2}{|c|}{ Group 2} \\
\hline & $\begin{array}{l}\text { Graft } \\
\text { taken }\end{array}$ & $\begin{array}{c}\text { Not } \\
\text { taken }\end{array}$ & $\begin{array}{l}\text { Graft } \\
\text { taken }\end{array}$ & $\begin{array}{c}\text { Not } \\
\text { taken }\end{array}$ \\
\hline Small & $6(100 \%)$ & 0 & $2(100 \%)$ & 0 \\
\hline Medium & $9(90 \%)$ & $1(10 \%)$ & $11(78.57 \%)$ & $3(21.43 \%)$ \\
\hline Large & $7(50 \%)$ & $7(50 \%)$ & $6(42.86 \%)$ & $8(57.14 \%)$ \\
\hline Total & $\begin{array}{c}22 \\
(73.33 \%)\end{array}$ & $\begin{array}{c}8 \\
(26.67 \%)\end{array}$ & $\begin{array}{c}19 \\
(63.33 \%)\end{array}$ & $\begin{array}{c}11 \\
(36.67 \%)\end{array}$ \\
\hline \multicolumn{5}{|c|}{$\begin{array}{l}\text { Table 8. Relationship between Size of } \\
\text { foration and Graft Uptake in both Groups }\end{array}$} \\
\hline
\end{tabular}

As the size of perforation increases chance of graft take up decreases.

Chi - square -7.5 , df -2 , $p$ value -.024 .

Graft uptake was complete in all the patients with small perforation (100\%) in group 2 also.

Chi - square -5.085 , df -2 , p value -.079 .

\begin{tabular}{|c|c|c|c|c|}
\hline \multirow{2}{*}{$\begin{array}{c}\text { Site of } \\
\text { Perforation }\end{array}$} & \multicolumn{2}{|c|}{ Group 1} & \multicolumn{2}{|c|}{ Group 2} \\
\hline & $\begin{array}{l}\text { Graft } \\
\text { Taken }\end{array}$ & $\begin{array}{c}\text { Not } \\
\text { Taken }\end{array}$ & $\begin{array}{c}\text { Graft } \\
\text { Taken }\end{array}$ & \begin{tabular}{|c|} 
Not \\
Taken
\end{tabular} \\
\hline Anterior & $10(100 \%)$ & 0 & $6(85.71 \%)$ & $1(14.29 \%)$ \\
\hline Posterior & $3(75 \%)$ & $1(25 \%)$ & $5(71.43 \%)$ & $2(28.57 \%)$ \\
\hline $\begin{array}{l}\text { Both Anterior } \\
\text { And Posterior }\end{array}$ & $9(56.25 \%)$ & 7 (43.75\%) & $8(50 \%)$ & $8(50 \%)$ \\
\hline Total & $\begin{array}{c}22 \\
(73.33 \%)\end{array}$ & \begin{tabular}{|c|}
8 \\
$(26.67 \%)$
\end{tabular} & $\begin{array}{c}19 \\
(63.33 \%)\end{array}$ & $\begin{array}{c}11 \\
(36.67 \%)\end{array}$ \\
\hline . & tion and & $\begin{array}{l}\text { ionship be } \\
\text { raft Uptak }\end{array}$ & $\begin{array}{l}\text { ween Site o } \\
\text { in both Gr }\end{array}$ & oups \\
\hline
\end{tabular}

In both groups, Graft uptake was maximum (100\%) in those with perforation involving only anterior half of tympanic membrane. In group 1 , Chi- square -6.03 , df -2 , $\mathrm{p}$ value 0.049

In group 2, Chi- square $-2.932, \mathrm{df}-2, \mathrm{p}$ value -0.231 .

\begin{tabular}{|c|c|c|c|c|}
\hline & \multicolumn{2}{|c|}{ Group 1 } & \multicolumn{2}{c|}{ Group 2 } \\
\hline $\begin{array}{c}\text { Middle Ear } \\
\text { Mucosa }\end{array}$ & $\begin{array}{c}\text { Graft } \\
\text { Taken }\end{array}$ & $\begin{array}{c}\text { Not } \\
\text { Taken }\end{array}$ & $\begin{array}{c}\text { Graft } \\
\text { Taken }\end{array}$ & $\begin{array}{c}\text { Not } \\
\text { Taken }\end{array}$ \\
\hline Pale & $22(84.62 \%)$ & $4(15.38 \%)$ & $19(70.37 \%)$ & $8(29.63 \%)$ \\
\hline Oedematous & 0 & $4(100 \%)$ & 0 & $3(100 \%)$ \\
\hline Total & $\begin{array}{c}\mathbf{2 2} \\
(\mathbf{7 3 . 3 3 \% )})\end{array}$ & $\begin{array}{c}\mathbf{8} \\
(\mathbf{2 6 . 6 7 \% )})\end{array}$ & $\begin{array}{c}\mathbf{1 9} \\
(\mathbf{7 3 . 3 3 \% )})\end{array}$ & $\begin{array}{c}\mathbf{1 1} \\
(\mathbf{2 6 . 6 7 \% )}\end{array}$ \\
\hline \multicolumn{3}{|c|}{$\begin{array}{c}\text { Table 10. Relationship between Middle Ear } \\
\text { Mucosa and Graft Uptake in both Groups }\end{array}$} \\
\hline
\end{tabular}

Group 1-Chi-square - 8.42, df-3, p value- 0.038 . 


\begin{tabular}{|c|c|c|c|c|}
\hline \multirow{2}{*}{$\begin{array}{c}\text { Eustachian } \\
\text { Tube } \\
\text { Function }\end{array}$} & \multicolumn{2}{|c|}{ Group 1} & \multicolumn{2}{|c|}{ Group 2} \\
\hline & $\begin{array}{c}\text { Graft } \\
\text { Taken }\end{array}$ & $\begin{array}{c}\text { Graft Not } \\
\text { Taken }\end{array}$ & $\begin{array}{c}\text { Graft } \\
\text { Taken }\end{array}$ & $\begin{array}{c}\text { Not } \\
\text { Taken }\end{array}$ \\
\hline Good & $\begin{array}{c}12 \\
(92.31 \%)\end{array}$ & $1(7.69 \%)$ & $\begin{array}{c}13 \\
(92.86 \%)\end{array}$ & $1(7.14 \%)$ \\
\hline Poor & $\begin{array}{c}10 \\
(58.82 \%)\end{array}$ & 7 (41.18\%) & $6(37.5 \%)$ & $10(62.5 \%)$ \\
\hline Total & $\begin{array}{c}22 \\
(73.33 \%)\end{array}$ & $8(26.67 \%)$ & $\begin{array}{c}19 \\
(63.33 \%)\end{array}$ & $\begin{array}{c}11 \\
(36.67 \%)\end{array}$ \\
\hline $\boldsymbol{I}$ & 1 Dotio & & Eustachic & $\begin{array}{l}\text { Tube } \\
\text { Tus }\end{array}$ \\
\hline
\end{tabular}

In both groups, Graft failure occurred in patients with poor Eustachian tube function. In group 1, Chi -square - 4.224, df- 1, p value -.04

In group 2, Chi -square - 9.853, df- 1, p value -.002.

\section{DISCUSSION}

The patients were grouped into two with 30 cases in each. In Group 1, dry temporalis fascia was used as graft material and in Group 2, wet temporalis fascia was used. Observations were as follows.

Age distribution of the study population ranged from 18 to 54 years. Majority of the patients were in the age group 21 30 years in both groups ( $43.3 \%$ in group 1 and $36.7 \%$ in group 2). In a study conducted by Sanjeev Kumar Thakur et $\mathrm{al}^{4}$ on outcome of tympanoplasty, the highest frequency was of the age group 21-30 years, similar to our study. Another study by Md. Zakaria Sarker et $\mathrm{al}^{5}$ showed majority of the patients (50\%) were among the age group 26-35 years.

Females were predominating in our study population. $66.7 \%$ were females in group 1 with a male to female ratio of $1: 2$ and $76.7 \%$ were females in group 2, with a sex ratio of 1:3.3. In the study by Sanjeev Kumar Thakur et al, females were more common than males ${ }^{4}$, similar to our study, with a sex ratio of female: male being 1.6:1. However, other studies like Geetanjali Jaiswani and Rajesh Kumar ${ }^{6}$ and Adnan Saleem Umar, Zubair Ahmed ${ }^{7}$ had males more common than females. Most of the patients who underwent surgery had ear discharge (100\% in group 1 and $96.7 \%$ in group 2), followed by hard of hearing (66.7\% in group 1 and $56.7 \%$ in group 2 ). A study done by Sharankumar Shetty ${ }^{8}$ showed that all the patients in their study presented with complaints of ear discharge and hearing loss.

Left-sided CSOM was more common (50\%) in group 1, whereas both sides were equally involved ( $40 \%$ each) in group 2. In study by Sanjeev Kumar Thakur et al, left was more (57\%) than right (43\%). ${ }^{4}$ But in a study by Adnan Saleem Umar and Zubair Ahmed, right-sided CSOM was more common. ${ }^{7}$ Both the right and left ears were nearly equally affected (right ear 51 and left ear 49 out of 100 cases) in a study by Shaikh et al. ${ }^{9}$

Majority (46.7\%) of patients in group 1 had large central perforations, whereas in group 2 large and medium-sized perforations were equally distributed ( $46.7 \%$ each). In study by Md. Zakaria Sarker et al the size of the perforation was graded as small (less than 50\%), medium (50-75\%) and large (> 75\%)..$^{5}$ In another study by Geetanjali Jaiswani and Rajesh Kumar had $21(26.3 \%)$ small (0-25\%) perforations, 27 $(33.75 \%)$ medium-sized (26 - 50\%) perforations and 32 $(40 \%)$ large (> 50\%) perforations. ${ }^{6}$

Most common approach used was transcanal $(90 \%$ in group 1 and $83.3 \%$ in group 2) in our study. In the study by
Rupesh Raj Joshi et al,10 the most common approach was postaural (76.92\%) followed by transcanal approach (13.46\%).

Hearing threshold of study population ranged from 13.3 $\mathrm{dB}$ to $66.6 \mathrm{~dB}$ in group 1 and $15 \mathrm{~dB}$ to $51.6 \mathrm{~dB}$ in group 2. The mean PTA of the population was $34.05 \mathrm{~dB}$ in group 1 and 33.92 $\mathrm{dB}$ in group 2. Statistical analysis was done using one-way analysis of variance(ANOVA) test and it was observed that with increasing size of perforation the degree of hearing loss increases ( $p$ value -.003 for group 1 and 0.000 for group 2). It was observed that site of perforation also influenced the degree of hearing loss, perforation involving both anterior and posterior half had the greatest hearing loss in both groups, followed by posterior perforations. Hearing loss was minimum in those patients with perforation involving anterior half only. Yung11 found that big central and posterior perforations have more hearing loss compared to other sites and that a posterior inferior perforation results in a greater hearing loss than anterior inferior one. Ahmad and Rahani ${ }^{12}$ also had similar finding with posterior perforation having more hearing loss than anterior ones. A study by Vaidya S, Sharma JK, Singh G13 noted more hearing loss in posterior perforations.

Middle ear mucosa was assessed at operation and it was normal in most of the patients in both groups. Only $13.3 \%$ and $10 \%$ had oedematous middle ear mucosa in group 1 and group 2 respectively. A study by P. Hari Krishna and T. Sobha Devi ${ }^{14}$ showed abnormal middle ear mucosal pathology such as polypoidal mucosa, granulations and tympanosclerosis in $42 \%$ of patients and normal mucosa in 58\%.

Of the total 60 cases, dry temporalis fascia was used in 30 cases (group 1) and wet temporalis fascia in 30 cases (group 2). There was $73.33 \%$ graft uptake in group 1 compared to $63.33 \%$ graft uptake in group 2. But the relation was not statistically significant, i.e, it has occurred only by chance (chisquare -.693, df $-1, \mathrm{p}$ value -.405). The total graft uptake was $68.33 \%$ which was higher than the result of study by Ajmal Hussain et $\mathrm{al}^{15}(60 \%)$, but less than many other studies like $78 \%$ for P. Hari Krishna and T. Sobha Devi,14 $82.69 \%$ for Rupesh Raj Joshi.10 The study by Alkan S et al,16 "Effect of the use of dry (rigid) or wet (soft) temporalis fascia graft on tympanoplasty" concluded that the temporalis fascia had high success rate regardless of its use, either wet or dry. Using wet grafts can shorten the operation time and result in a high number of fibroblast nuclei histologically. In their study, the success rate was $91.4 \%$ in the wet graft group and $88.6 \%$ in the dry graft group. Another study by Lock J.W and Naude $\mathrm{N}^{17}$ compared graft uptake with fresh, dried and dried then rehydrated temporalis fascia and the success rates were $89 \%$, $84 \%$ and $85 \%$ respectively. They concluded that while the desiccation of temporalis fascia prior to use in myringoplasty results in degeneration of cellular and stromal elements histologically, this does not affect the successful closure of perforations.

Relationships of graft uptake with other factors like age of patient, size and site of perforation, middle ear mucosal status and Eustachian tube function were analysed in the study population using chi-square test. In group 1, there was a significant difference in graft uptake between the different age groups studied, with 18-20 age group having maximum graft uptake (100\%) followed by 21 - 30 age group (92.3\%). Graft uptake was least in $>40$ years $(25 \%)$, i.e. with increasing age the graft uptake was decreasing (Chi-square - 8.42, df-3, p value-0.038). In group 2 , maximum graft uptake was in the age 
group 21-30 years (90.9\%). There was no significant relationship in graft uptake between different age groups in group 2 (chi-square -7.066, df-3, p value - 0.07). A study conducted by Khan Feroze $\mathrm{K}^{18}$ et al on factors affecting outcome of tympanoplasty found that better success rate with middle age group (21-45 yrs.). Another study by Sanjeev Kumar Thakur et al found that the age factor did not influence the success rate in terms of graft success. ${ }^{4}$ However, a recent study in Nepal Medical College by Rupesh Raj Joshi et al concluded that the graft takes rate was better with the advancing ages. ${ }^{10}$ According to Lee and Schuknecht ${ }^{19}-1971$, age has no significant role in success of Tympanoplasty.

Graft uptake was complete in all the patients with small perforation $(100 \%)$ in both groups, compared to $90 \%$ for medium and $50 \%$ for large in group 1 and $78.57 \%$ for medium and $42.86 \%$ for large perforation in group 2, i.e. as the size of perforation increases chance of graft taking decreases. Similar to our study, Lee et $\mathrm{al}^{19}$ found the success rate for small perforations higher (74.1\%) compared to large perforations (56\%). According to the study by Vaidya S, Sharma JK, Singh G, larger perforations showed more residual hearing loss and graft failure followed by medium-sized perforations.

Site of perforation also influenced the graft uptake. In those with perforation involving only anterior half of tympanic membrane graft was taken in $100 \%$ in group 1 and $85.71 \%$ in group 2, but in case of perforation involving both anterior and posterior half graft was taken only in $56.25 \%$ in group 1 and $50 \%$ in group 2 . This relation was significant for group 1 (chisquare -6.03 , df-2, p value -.049). The influence of the location of the perforation on surgical outcome after tympanoplasty has frequently been an issue of interest. The location of the perforation reportedly had no effect on the surgical results in some studies (Tympanoplasty type 1 in children). However, Pinar et $\mathrm{al}^{20}$ found that the rate of graft success was higher for central perforations than for posterior and anterior perforations. According to study by Rupesh Raj Joshi et al,10 the graft take rate in cases of posterior and anterior perforation were $88.89 \%$ and $84.21 \%$ respectively which was significantly more than that of subtotal perforation $73.33 \%$. But in Md. Zakaria Sarker et $\mathrm{al}^{5}$ study, Graft take rate was more in central perforation $(83.79 \%)$ than posterior central $(82.35 \%)$ and anterior central (66.67\%). Khan Feroze K et al 18 found that best result was for posterior perforations and central perforations. It was worse for anterior perforations and bad for subtotal perforations. This correlated with many other studies available. Many authors have reported less success with anterior perforations probably because the anterior portion of the tympanic membrane is the least vascular area and most difficult area to access.

Graft was not taken in $100 \%$ patients with oedematous middle ear mucosa in both groups. Thus, if there is mucosal oedema or hyperplasia, this may mean poor aeration of the middle ear suggesting disease activity ( $p$ value -0.000 for group 1 and 0.016 for group 2). Khan Feroze $\mathrm{K}$ et al ${ }^{18}$ found that in the inactive stage there was $96.9 \%$ success, for quiescent it was $84.9 \%$ and for active stage it was $67.9 \%$. This also correlated with most of the other studies. But Halik et al ${ }^{21}$ found that the type of middle ear secretion present at surgery had no effect on the result. Mills et $\mathrm{a}^{22}$ found no clinically significant difference in the success rate for myringoplasty in patients whose ears were active or inactive at the time of surgery.
It was observed that in our study there was significant relationship between Eustachian tube function and graft uptake. Graft was taken in $92.31 \%$ of patients with good Eustachian tube function, but only in $58.82 \%$ of cases with poor Eustachian tube function in group 1. In group 2, graft was taken only in $37.5 \%$ of cases with poor Eustachian tube function, compared to $92.86 \%$ uptake in case of good Eustachian tube function. Holmquist et $\mathrm{al}^{23}$ found that in the group with good tubal function there was $75 \%$ healing and only $16 \%$ of the patients had perforations. In the hypofunction group, almost $90 \%$ failed. Study by Manning et al $^{24}$ found that good eustachian tube function was shown to predict good outcome, but poor tubal function was not helpful in predicting poor outcome. Many authors agree that preoperative abnormalities indicative of severity of underlying Eustachian tube dysfunction and infection have a significant influence on prognosis.

\section{CONCLUSION}

Majority of the patients in dry and wet fascia groups belong to third decade. Females were predominating in both groups. Ear discharge was the most common presenting complaint in both groups. Left-sided CSOM was more common in in group 1 (dry temporalis fascia graft), whereas both sides were equally affected in group 2 (wet temporalis fascia graft). Large central perforation was more common in group 1 . Medium-sized and large perforations were equal in group 2 . In both the groups, majority of the patients had perforation involving both anterior and posterior half of tympanic membrane. Hearing loss was maximum in those patients with large central perforation and perforation involving both anterior and posterior half of tympanic membrane in both groups. Most common approach used was transcanal route. There was $73.33 \%$ graft uptake rate in group 1 (dry temporalis fascia graft) compared to $63.33 \%$ in group 2 (wet temporalis fascia graft). Graft failure occurred in $26.67 \%$ patients of group 1 and $36.67 \%$ patients of group 2. Graft uptake was maximum for the age group 18-20 years in group 1 and 21-30 years in group 2 . In group 1, graft failure was more as the age advances. Graft uptake was complete in all the patients with a small perforation in both groups. Graft uptake was maximum in those patients with perforation involving only anterior half of tympanic membrane in both groups.

In those with oedematous middle ear mucosa, there was $100 \%$ graft failure, in both groups. In those with poor Eustachian tube function, graft failure occurred in $41.18 \%$ in group 1 and $62.5 \%$ in group 2.

\section{REFERENCES}

[1] Acuin J. Chronic suppurative otitis media-burden of illness and management options. Geneva: World Health Organization 2004.

[2] Singh B, Maharaj TJ. Radical mastoidectomy: its place in otitic intracranial complications. Journal of Laryngology and Otology 1993;107(12):1113-8.

[3] Lierle DM. Committee on Conservation of Hearing, American Academy of Ophthalmology and Otolaryngology. Standard classification for surgery of chronic ear disease. Arch Otol 1965;81(2):204-5.

[4] Thakur SK, Singh SK, Afaque A, et al. Outcome of type 1 tympanoplasty: an experience at Biratnagar Eye Hospital in Eastern Nepal. Asian J Med Sci 2016;7(2):55-60. 
[5] Sarker MZ, Ahmed M, Patwary K, et al. Factors affecting surgical outcome of myringoplasty. Bangladesh J Otorhinolaryngol 2011;17(2).

[6] Jaiswani G, Kumar R. Impact of age on outcome of type 1 tympanoplasty. Online J Otolaryngol 2014;4(4):129-34.

[7] Umar AS, Ahmed Z. Anatomical and functional outcome following type-1 tympanoplasty in chronic tubotympanic suppurative otitis media. Pak Armed Forces Med J 2008;1:1-5.

[8] Shetty S. Pre-operative and post-operative assessment of hearing following tympanoplasty. Indian J Otolaryngol Head Neck Surg 2012;64(4):377-81.

[9] Shaikh AA, Onali MAS, Shaikh SM, et al. Outcome of tympanoplasty type-I by underlay technique. J Liaquat Univ Med Health Sci 2009;8(1):80-4.

[10] Joshi RR, Jha AK, Rijal AS, et al. Hearing evaluation after myringoplasty at Nepal medical college and teaching hospital. Journal of Nobel Medical College 2013;2(3):3642.

[11] Yung MW. Myringoplasty: hearing gain in relation to perforation site. J Laryngol Otol 1983;97(1):11-7.

[12] Ahmed SW, Rahani GV. Hearing loss in perforations of the tympanic membrane. J Laryngol Otol 1979;93(11):10918.

[13] Vaidya S, Sharma JK, Singh G. Study of outcome of tympanoplasties in relation to size and site of tympanic membrane perforation. Indian J Otolaryngol Head Neck Surg 2014;66(3):341-6.

[14] Krishna PH, Devi TS. Clinical study of influence of prognostic factors on the outcome of tympanoplasty surgery. IOSR Journal of Dental and Medical Sciences 2013;5(6):41-5.

[15] Hussain A, Yousaf N, Khan AR. Outcome of myringoplasty. Jrnl of PG Med Inst Peshawar 2004;18(4):695-8.
[16] Alkan S, Baylanĉiĉek S, Sözen E, et al. Effect of the use of dry (rigid) or wet (soft) temporal fascia graft on tympanoplasty. J Otolaryngol-Head Neck Surg 2009;38(1):126-32.

[17] Loock JW, Naude N. A randomised controlled trial comparing fresh, dried, and dried-then-rehydrated temporalis fascia in myringoplasty. Clin Otolaryngol 2008;33(2):97-101.

[18] Feroze K, Rejee E, Sajilal M. Assessment of factors affecting the outcome of myringoplasty and type-1 tympanoplasty. International Journal of Biomedical Research 2014;5(5).

[19] Lee K, Schuknecht HF. Results of tympanoplasty and mastoidectomy at the Massachusetts eye and ear infirmary. Laryngoscope 1971;81(4):529-43.

[20] Pinar E, Sadullahoglu K, Calli C, et al. Evaluation of prognostic factors and middle ear risk index in tympanoplasty. Otolaryngol Head Neck Surg 2008;139(3):386-90.

[21] Halik JJ, Smyth GDL. Long-term results of tympanic membrane repair. Otolaryngol Head Neck Surg 1988;98(2):162-9.

[22] Mills R, Thiel G, Mills N. Results of myringoplasty operations in active and inactive ears in adults. The Laryngoscope 2013;123(9):2245-9.

[23] Holmquist J. The role of the eustachian tube in myringoplasty. Acta Otolaryngol (Stockh) 1968;66(16):289-95.

[24] Manning SC, Cantekin EI, Kenna MA, et al. Prognostic value of eustachian tube function in pediatric tympanoplasty. The Laryngoscope 1987;97(9):1012-6. 